\title{
Prevalência de cetose no deslocamento de abomaso em bovinos leiteiros
}

Leonardo Luiz Dametto;, Sergio Pauls, Miguel Spagnol, Rogério Carvalho Souza, Rafahel Carvalho de Souza

LMS Assessoria Veterinária, Tapejara, RS, Brasil

*Autor correspondente

e-mail: lldametto@yahoo.com.br

\section{Resumo}

Na intenção de ser mais eficiente na bovinocultura leiteira, a intensificação no melhoramento genético dos animais busca obter o máximo de produção por unidade animal. Todavia, para conseguir mais eficiência são necessários manejo e alimentação mais adequados, pois quando realizados de forma inadequada, podem refletir em alterações metabólicas, sendo as vacas de alta produção as mais susceptíveis. Cetose e deslocamento de abomaso (DA) são enfermidades que se encaixam neste perfil de doenças metabólicas da bovinocultura moderna. Cetose é uma desordem metabólica relacionada ao metabolismo energético que acomete mamíferos. Já o deslocamento de abomaso é uma doença multifatorial, de ocorrência nas primeiras seis semanas após o parto. A principal causa do DA é a atonia do abomaso, já que a não eliminação e, consequente, acúmulo dos gases produzidos favorece o seu deslocamento. Sinais clínicos observados são redução do apetite e diminuição na produção. 0 presente trabalho relata a prevalência de cetose subclínica em animais com DA, na região nordeste do estado do Rio Grande do Sul, em 2016. Os dados foram compilados por médicos veterinários em seus atendimentos de rotina. Para todos os animais que eram submetidos à cirurgia de DA, tanto para esquerda quanto para direita, antes do procedimento era mensurado a concentração de corpos cetônicos pelo método de diagnóstico eletrônico rápido a campo, utilizando o aparelho portátil KetoVet ${ }^{\circledR}$ (KetoVet Brazil, TaiDoc Technology, Taiwan). Imediatamente após a amostragem de sangue da veia ou artéria coccígea, o volume de uma gota de sangue foi colocado em tira do reagente teste para beta-cetonas, já previamente inserida em aparelho portátil KetoVet ${ }^{\circledR}$. Para todos os efeitos, foi considerado animal clinicamente normal para cetose todos aqueles com concentração molar de corpos cetônicos igual ou menor que 1,1 mmol/L, e subclínica todos aqueles cuja concentração molar foi igual ou superior a 1,2 mmol/L, sem sinais clínicos. Foram avaliados 36 animais, dos quais 27 tinham DA à esquerda (DAE) e índices de beta-cetona igual ou acima de 1,2 mmol/L, e nove tinham DA à direita e índices 
de beta-cetona abaixo ou igual a 1,1 mmol/L. A prevalência de cetose subclínica foi alta em animais com DA; tal patologia, por afetar o consumo de alimentos, pode fazer com que o animal mobilize suas reservas energéticas, aumentando assim a produção de corpos cetônicos. Desta forma, sugere-se que além de corrigir o DA, deve-se dar importância às doenças secundárias que possam estar envolvidas para a melhora do animal. 